\title{
MEDIA POROSITY in SILK WORM CULTURE (Tubifex sp.)
}

\author{
Epro Barades $^{1}$ · Pindo Witoko ${ }^{1}$
}

\begin{abstract}
The content of organic matter can affect the growth of silk worms (Tubifex sp.). In addition, media porosity can also have an effect. This study aims to determine the effect of porosity on the cultivation of silk worm by using media of mud and sandy mud. The analysis used a complete randomized design method with three replications. The silk worm population in mud and sandy mud is 521 and 984, with $A B W$ (Average Body Weight) growth of $0.3 \mathrm{mg}$ and $0.1 \mathrm{mg}$. These results prove that porosity affects the population, whereas organic matter affects the weight of silk worms. So it can be concluded that the use of sandy mud media produces a higher population, but has lower $A B W$ than the mud media.
\end{abstract}

Keywords mud, sandy mud, population, $A B W$

Received : 11 Oktober 2017

Accepted : 27 Nopember 2017

\section{PENDAHULUAN}

Cacing sutra sangat dibutuhkan dalam pembenihan ikan karena mengandung protein 5257\% (Pardiansyah, 2014). Pemberian pakan menggunakan cacing sutra dalam pembenihan dapat

$\left.{ }^{1}\right)$ Program Studi Budidaya Perikanan, Politeknik Negeri Lampung J1. Soekarno Hatta No.10 Rajabasa, Bandar Lampung 35144

E-mail: eprobarades@polinela.ac.id meningkatkan kelangsungan hidup dan laju pertumbuhan dari benih. Pertumbuhan ikan betutu menggunakan cacing sutra lebih tinggi dibandingkan dengan pemberian pakan pellet (Anggraeni and Abdulgani, 2013).

Cacing sutra dapat tumbuh dengan baik pada perairan yang memiliki kandungan bahan-bahan organik tinggi (Haryanti and Hidajati, 2013). Penelitian tentang cacing sutra menggunakan bahan organik telah dilakukan (Rahman, 2012); (Nurfitriani et al., 2014); (Pardiansyah et al., 2014); (Mi'raizki et al., 2015), dan (Laarhoven et al., 2016). Selain kandungan bahan organik, porositas tanah mungkin berpengaruh dalam budidaya cacing sutra.

Porositas adalah pori-pori dalam satuan volume tanah yang dapat ditempati oleh air dan udara. Porositas mencerminkan tingkat kesarangan tanah untuk dilalui aliran massa air atau kecepatan aliran air untuk melewati massa tanah (Hanafiah, 2005). Penelitian tentang produktivitas budidaya cacing sutra (Oligochaeta) dalam sistem resirkulasi menggunakan jenis substrat dan sumber air yang berbeda pernah dilakukan oleh Syam (2012). Penelitian tersebut menggunakan media pasir dan media lumpur dengan sumber air budidaya dan sumur. Sedangkan pada penelitian ini dilakukan pencampuran media pasir dengan lumpur dan media lumpur dengan sumber air sumur. Sehingga penelitian ini bertujuan untuk lebih memahami pengaruh porositas terhadap budidaya cacing sutra. 


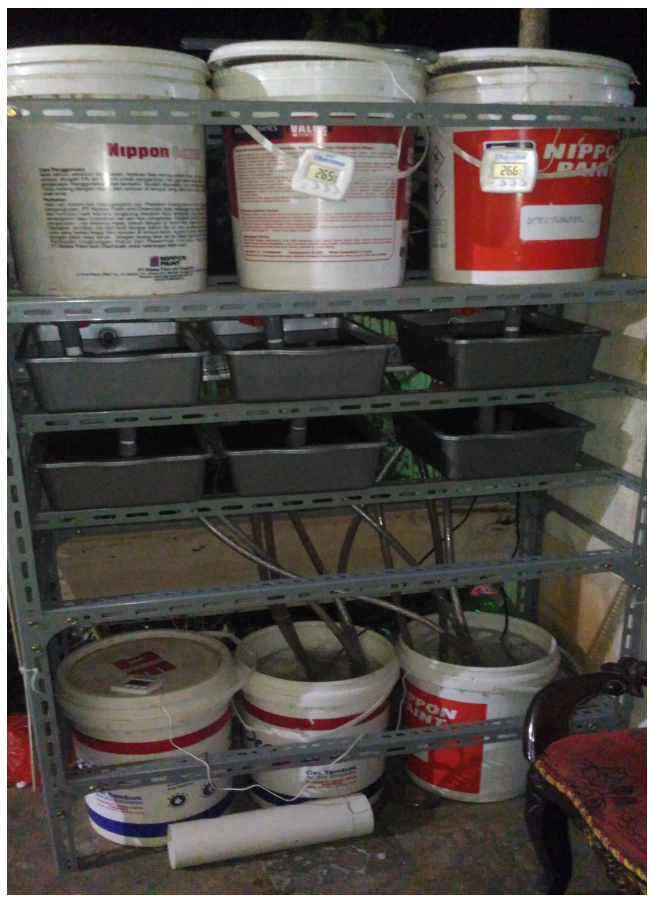

Figure 1 Sistem Pengairan Tertutup Budidaya Cacing Sutra(Resirkulasi)

\section{MATERI DAN METODE}

Rancangan yang dipakai adalah rancangan acak lengkap (RAL) dengan 2 perlakuan dan 3 kali ulangan. Perlakuan media pemeliharaan cacing sutra menggunakan lumpur dan lumpur berpasir. Media budidaya cacing sutra dipersiapkan sesuai dengan perlakuan dan dimasukkan dalam wadah budidaya berupa baskom plastik (ukuran $38 \mathrm{~cm}$ x $32 \mathrm{~cm} \mathrm{x} 12 \mathrm{~cm}$ ) setebal $3 \mathrm{~cm}$ dan digenangi air setinggi $2 \mathrm{~cm}$.

Penebaran cacing dilakukan setelah penggenangan wadah (setelah air jernih di dalam wadah). Cacing dibersihkan, ditimbang dan ditebar secara merata ke media perlakuan masing-masing 10 gram. Sistem pengairan yang digunakan adalah sistem tertutup yang artinya penggunaan air kembali atau resirkulasi (Gambar 1). Air dari wadah pemeliharaan dimasukkan dalam filter kemudian dialirkan kembali menuju wadah pemeliharaan. Sistem tersebut bertujuan untuk mengurangi penggunaan sumberdaya air dengan lahan yang terbatas. Debit aliran yang digunakan sebesar 500 ml.menit-1 (Puspitasari, 2012). Debit air yang masuk ke dalam wadah diatur dengan menggunakan kran pada selang pemasukkan.
Pemanenan dilakukan setelah cacing sutra dipelihara selama 20 hari. Pemanenan dengan mengacu pada metode panen yang dilakukan oleh (Cahyono et al., 2015). Parameter yang diamati dalam penelitian meliputi populasi, biomassa, ABW (Average Body Weight), dan TOM (Total Organic Matter).

\section{HASIL DAN PEMBAHASAN}

Perbedaan mendasar dari kedua media yang digunakan dapat terlihat pada porositas media. Media lumpur berpasir (sandy loam) menunjukkan tingkat porositas yang lebih tinggi dibandingkan dengan media lumpur (loam). Penggunaan kedua jenis media tersebut dalam budidaya cacing sutra memberikan hasil yang tidak berbeda nyata secara statistik $(\mathrm{P}>0.05)$. Populasi akhir setelah pemeliharaan selama 20 hari di media lumpur berpasir menunjukkan adanya peningkatan jumlah 984 ekor. Jumlah tersebut lebih banyak 463 ekor dibandingkan populasi di media lumpur (Gambar 2a). Respon reproduksi yang terjadi pada kondisi tersebut disebabkan oleh kurangnya makanan yang ada dalam media, sehingga cacing sutra mengalami stress dan melakukan reproduksi. Laarhoven et al. (2016) melakukan uji coba budidaya Lumbricus variegatus dalam media agar yang dicampur pasir, tanpa menggunakan pakan tambahan menunjukkan adanya penurunan $\mathrm{ABW}$, namun terjadi peningkatan jumlah populasi.

Penggunaan pasir dalam media budidaya cacing sutra berpengaruh pada porositas media, semakin banyak pasir yang digunakan akan semakin tinggi porositas dalam budidaya cacing sutra. Porositas tersebut mempengaruhi kemampuan media dalam mengumpulkan bahan organik yang ada di perairan. Penggunaan media pasir dengan sumber air yang berasal dari budidaya lele memberikan hasil pertumbuhan lebih baik dibandingkan dibandingkan media lumpur (Syam, 2012). Hal tersebut membuktikan bahwa porositas media berpengaruh terhadap jumlah bahan organik yang tertahan di media.

Perbedaan populasi yang hampir mendekati 500 ekor hanya memiliki selisih biomassa dari kedua perlakuan sebesar 0.7 gram (Gambar 2b). 

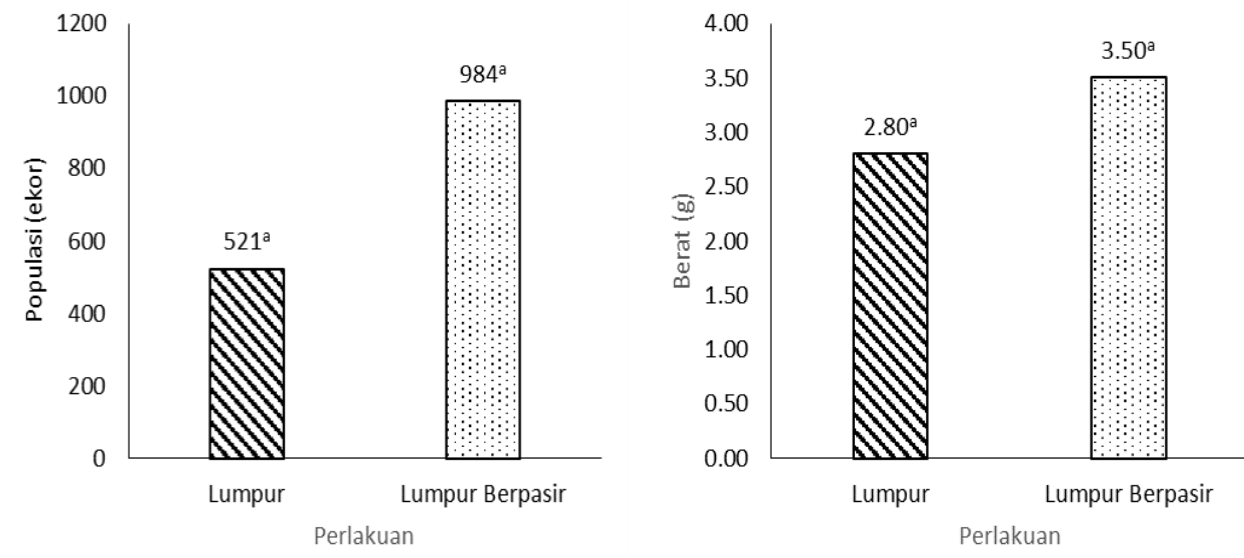

Figure 2 Pertumbuhan Populasi (a) dan Biomassa (b) cacing sutra

Jumlah populasi yang berbeda namun memiliki berat hampir sama kemungkinan besar disebabkan oleh adanya pengaruh dari ABW cacing sutra. Pertumbuhan ABW pada cacing sutra yang dipelihara di media lumpur lebih tinggi dibandingkan dengan media lumpur berpasir, masing-masing $0.3 \mathrm{mg}$ dan $0.1 \mathrm{mg}$.

Pertumbuhan ABW cacing sutra dipengaruhi oleh bahan organik yang terdapat dalam media. Laarhoven et al. (2016) menyatakan bahwa cacing yang dipelihara dengan tambahan bahan organik akan menghasilkan pertumbuhan berat yang lebih baik. Tinggi rendahnya bahan organik dalam media pemeliharaan dapat diketahui dengan mengukur kandungan TOM pada media tersebut. Kandungan TOM pada media lumpur lebih tinggi dibandingkan dengan media Lumpur berpasir (Gambar 3). Oleh karena itu, media lumpur mengandung bahan organik yang lebih tinggi dibandingkan media lumpur berpasir. Kandungan bahan organik tersebut berpengaruh pada peningkatan $\mathrm{ABW}$ cacing sutra yang dipelihara di media lumpur menjadi lebih tinggi.

Pemberian komposisi bahan organik yang tepat akan meningkatkan efisiensi dalam budidaya cacing sutra. Hossain et al. (2012) melakukan penelitian tentang rasio media dalam budidaya cacing sutra. Penelitian tersebut membuktikan bahwa penggunaan campuran media yang tepat dapat mengurangi kebutuhan media sebesar 50\% dengan hasil budidaya yang sama. Selain itu penggunaan sistem resirkulasi juga berpengaruh terhadap pertumbuhan dan produktivitas budidaya cacing sutra. Sistem resirkulasi menghasilkan biomassa dan populasi yang lebih tinggi dibandingan dengan sistem sirkulasi (Nur, 2014). Hal tersebut berhubungan dengan terbilasnya bahan organik dalam media. Apabila sistem yang digunakan adalah sistem sirkulasi maka bahan organik akan terbilas, sedangkan penggunaan sistem resirkulasi mengakibatkan bahan organik tetap berada dalam air media pemeliharaan.

Selama pemeliharaan kandungan TOM dalam media pemeliharaan mengalami penurunan. Penurunan terjadi pada kedua media pemeliharaan masing-masing $7.32 \%$ dan $6,48 \%$. Hal tersebut membuktikan bahwa ABW yang dihasilkan dalam budidaya cacing mempengaruhi kandungan bahan organik media. Semakin tinggi ABW cacing sutra akan semakin cepat menurunkan kandungan bahan organik dalam media. Akan tetapi, biomassa cacing sutra lebih tinggi pada media lumpur berpori dibandingkan media lumpur. Sehingga diduga porositas pada media lumpur berpasir membuat cacing sutra dapat dengan mudah mendapat makanan dari sumber lain selain dari media lumpur berpasir. Hossain et al. (2012) menyatakan bahwa variasi hasil yang diperoleh dalam produksi cacing sutra dapat dipengaruhi oleh kandungan nutrisi dan pasir dalam media budidaya.

\section{SIMPULAN}

Porositas media mempengaruhi pertumbuhan populasi cacing sutra. Penggunaan media lumpur berpasir menghasilkan populasi yang lebih tinggi 


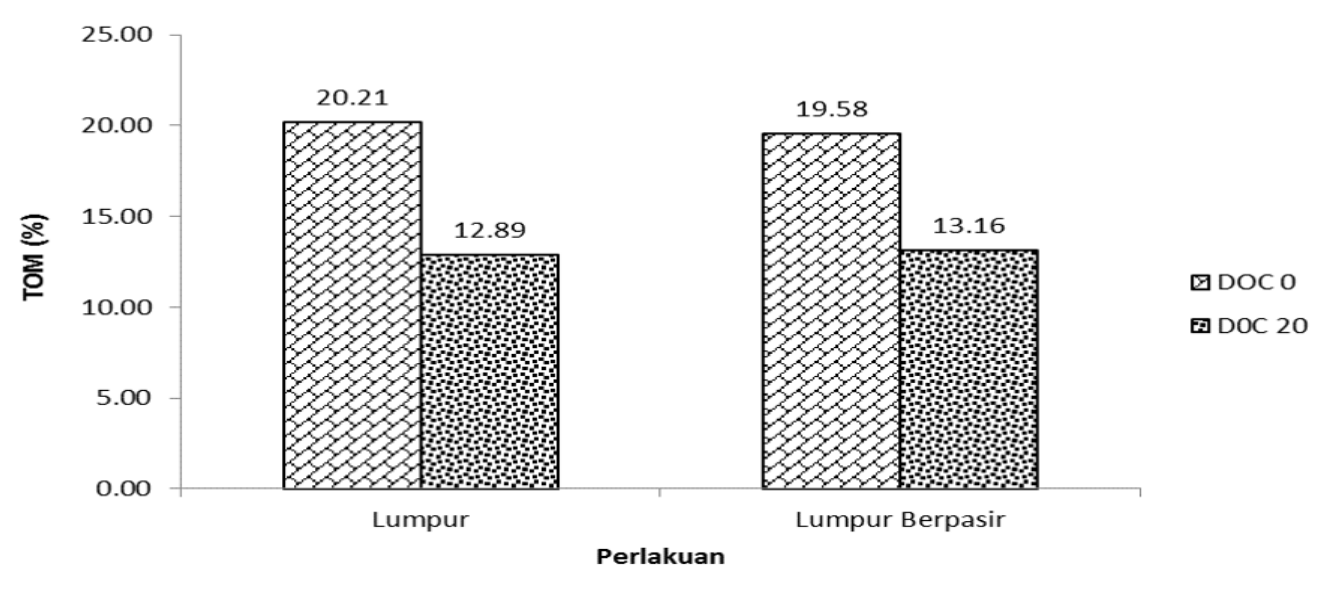

Figure 3 Kandungan TOM media pemeliharaan

dengan ABW yang lebih rendah dibandingkan media lumpur. Sehingga perlu dilakukan penelitian lebih lanjut untuk mendapatkan campuran media lumpur dan pasir yang optimal untuk budidaya cacing sutra.

Acknowledgements Terima kasih kepada Politeknik Negeri Lampung (POLINELA) yang telah memberikan bantuan materi sehingga penelitian ini dapat terlaksana dan terselesaikan tepat pada waktunya.

\section{References}

Anggraeni, N. M. and Abdulgani, N. (2013). Pengaruh pemberian pakan alami dan pakan buatan terhadap pertumbuhan ikan betutu (oxyeleotris marmorata) pada skala laboratorium. Jurnal Sains dan Seni ITS, 2(2):E197-E201.

Cahyono, E. W., Hutabarat, J., and Herawati, V. E. (2015). Pengaruh pemberian fermentasi kotoran burung puyuh yang berbeda dalam media kultur terhadap kandungan nutrisi dan produksi biomassa cacing sutra (tubifex sp.). Journal of Aquaculture Management and Technology, 4(4):127-135.

Hanafiah, K. A. (2005). Dasar-dasar ilmu tanah. PT RajaGrafindo Persada.

Haryanti, D. N. and Hidajati, N. (2013). Pengaruh metode pengeringan terhadap kualitas tepung cacing sutra (tubifex sp.)(effect of drying method of wheat quality silk worms (tubifex sp.)). UNESA Journal of Chemistry, 2(3).

Hossain, A., Mollah, M., and Hasan, M. (2012). Ratio optimisation of media ingredients for mass culture of tubificid worms (oligochaeta, tubificidae) in bangladesh. Asian Fisheries Science, 25:357-368.

Laarhoven, B., Elissen, H., Temmink, H., and Buisman, C. (2016). Agar sediment test for assessing the suitability of organic waste streams for recovering nutrients by the aquatic worm lumbriculus variegatus. PloS one, 11(3):e0149165.
Mi'raizki, F., Chilmawati, D., and Suminto, S. (2015). Pengaruh pengkayaan nutrisi media kultur dengan susu bubuk afkir terhadap kuantitas dan kualitas produksi cacing sutera (tubifex sp.). Journal of Aquaculture Management and Technology, $4(2): 82-91$.

Nur, I. M. (2014). Kinerja produksi budidaya cacing oligochaeta dengan sistem sirkulasi dan resirkulasi. Master's thesis, Institut Pertanian Bogor.

Nurfitriani, L., Hutabarat, J., et al. (2014). Pengaruh penambahan kotoran ayam, ampas tahu dan silase ikan rucah dalam media kultur terhadap biomassa, populasi dan kandungan nutrisi cacing sutera (tubifex sp.). Journal of Aquaculture Management and Technology, 3(4):109-117.

Pardiansyah, D., Supriyono, E., and Djokosetiyanto, D. (2014). Pemanfaatan limbah budidaya ikan lele (clarias sp) sistem bioflok untuk budidaya cacing sutra (tubificidae).

Puspitasari, A. (2012). Peningkatan rasio $\mathrm{c} / \mathrm{n}$ dengan penambahan tepung tapioca pada substrat budidaya cacing sutra (oligochaeta) sistem resirkulasi. Master's thesis, Institut Pertanian Bogor.

Rahman, J. (2012). Efektivitas penggunaan berbagai pupuk kandang yang difermentasi pada budidaya cacing sutra oligochaeta.

Syam, F. S. (2012). Produktivitas budidaya cacing sutra (oligochaeta) dalam sistem resirkulasi menggunakan jenis substrat dan sumber air yang berbeda. 